\title{
М.Б. Бакеев
}

Центр истории и методологии экономической науки НИУ ВШЭ, Москва

\section{Институциональное и культурное направления в экономике развития: предпосылки относительно мотивации агентов как источник разногласий}

\begin{abstract}
Аннотация. В статье исследуются методологические расхождения, существующие между институциональным и культурным подходами в современной литературе, посвященной исследованию оснований экономического развития в долгосрочной перспективе. Детально анализируются и сравниваются онтологические предпосылки теорий ключевых представителей институционального (Д. Аджемоглу, Дж. Робинсон и Д. Норт) и культурного направлений (Дж. Мокир, Д. Макклоски). Утверждается, что традиционные способы концептуализации не позволяют выявить действительный источник методологических разногласий, существующих между этими исследовательскими подходами. Доказывается, что причиной данных разногласий являются различия в имплицитных онтологических предпосылках относительно мотивации агентов между рассматриваемыми теориями. Авторы институциональных теорий, не считающие необходимым присваивать культурным факторам самостоятельную роль, наряду с институциональными отказываются (на уровне онтологических предпосылок) от возможности экзогенных изменений внутренней мотивации агентов. В то же время авторы культурных теорий, для которых характерно выделение не зависимых друг от друга институциональных и культурных факторов, допускают существование в своих теориях экзогенных шоков во внутренней мотивации и их потенциально важную роль в экономических изменениях. Данное расхождение обуславливает дедуктивный характер аналитических нарративов в рамках институционального направления и индуктивный характер исторической аргументации представителей культурного направления.
\end{abstract}

Ключевые слова: институты, культура, экономическое развитие, идеи, онтологические предпосылки, научные споры, мотивачия.

Классификация JEL: B2, B4, B5, N10, O11, O31, Z13.

DOI: $10.31737 / 2221-2264-2020-46-2-7$

\section{1. Введение}

Наше понимание онтологии в экономике основывается на взгляде, выработанном в рамках постпозитивистских направлений методологии экономической науки в последние десятилетия. Оно предполагает трактовку онтологий как наборов базовых предпосылок, неопровержимых в рамках исследовательской программы (Ананьин, 2013, с. 18). На основе этих эксплицитных и имплицитных предпосылок конструируются модельные миры, которые исследуются теоретической экономикой.

$\mathrm{C}$ нашей точки зрения, расхождения в онтологических предпосылках между научными подходами иногда становятся скрытой причиной теоретических разногласий. В частности, в этой статье мы обра- 
щаем внимание на роль онтологических предпосылок в формировании подобных разногласий между институциональным и культурным подходами в современной теории экономического развития.

Один из способов анализа экономического развития укладывается в широкую традицию исследования причин успеха развитых стран на фоне неудач развивающихся. Работы в рамках этой традиции имеют давнюю историю, однако особую популярность они получили в последние десятилетия. Эти исследования на стыке экономической истории и экономики развития пытаются ответить на вопрос, понимая его в историческом ключе. Если традиционная теория экономического развития основное внимание уделяет проблемам бедных стран, имплицитно принимая успех развитых стран за стандартное состояние, то для данной традиции, напротив, бедность является рутиной и основная задача состоит в том, чтобы понять, как богатые страны в прошлом сумели уйти от этой рутины бедности. Разные авторы здесь указывают на самые разные причины: это может быть доступ к определенным ресурсам и географическое положение (Diamond, 1998), уровень реальной заработной платы (Allen, 2015), накопление человеческого капитала (Galor, 2011), генетические изменения (Clark, 2007) и т.д.

В этой статье мы рассмотрим исследования, усматривающие причины успеха современных развитых стран либо в определенных институтах, либо в определенной культуре. Необходимо отметить, что речь не идет обо всех исследованиях, в той или иной форме рассматривавших институциональные и культурные факторы экономического развития. Круг исследуемых нами теорий ограничивается получившими развитие в 2000-2010-е годы теориями, в той или иной степени связанными с традицией новой институциональной экономики (далее - неоинституционализма).

Во многом возникшие между институциональными и культурными подходами разногласия были спровоцированы атакой на методологию неоинституционализма со стороны Дейдры Макклоски, предложившей альтернативное объяснение движущих сил экономического развития в долгосрочной перспективе по сравнению с наиболее популярными институциональными теориями Дугласа Норта и Дарона Аджемоглу с соавторами (McCloskey, 2006, 2010, 2016a). Макклоски сознательно представила свои аргументы в остро полемической форме, что стало одной из причин возникшей в литературе дискуссии по поводу методологических и онтологических оснований исследовательской программы неоинституционализма, в частности применительно к проблеме экономического развития (см., например, (McCloskey, 2016b, 2017; Greif, Mokyr, 2016; Tabellini, 2016; Weingast, 2016; Boudreaux, 2014)).

Новые культурные подходы, о которых пойдет речь в статье, включающие, в частности, теорию Макклоски, тесно связаны с «идейным» и «нарративным» поворотами, которые произошли в течение 
последних двух десятилетий в социально-экономических исследованиях (Тамбовцев, 2019). В них большее внимание уделяется динамичным, изменяющимся компонентам культуры, которые часто схватываются через концепты идей и нарративов.

Как представляется, сама по себе оптика противопоставления институтов и культуры не проясняет понимания рассматриваемой нами литературы, потому что в действительности, во-первых, ни один автор не утверждает абсолютной незначимости институтов, и, во-вторых, различия между институтами и культурой имеют принципиальное значение в контексте теории только для некоторых авторов.

С точки зрения спора «институты или культура» рассматриваемые подходы, как нам представляется, можно разделить на четыре группы. Первая, представителем которой является теория Аджемоглу и Робинсона (далее - АиР) (Acemoglu, Robinson, 2012), предполагает жесткое противопоставление институтов и культуры при фактической незначимости культуры для экономического развития. Вторая группа, представителем которой, например, является теория Норта-УоллисаВайнгаста (далее - НУВ) (North, Wallis, Weingast, 2009), предполагает либо приравнивание культуры к определенному классу институтов, либо использование понятий «институт» и «культура» для описания тесно связанных элементов единого объясняющего механизма. Для третьей, куда можно отнести теорию Джоэля Мокира (Mokyr, 2016, 2018), характерно более четкое разделение институтов и культуры с указанием на более или менее равную важность обоих. Наконец, в рамках четвертой группы, куда относится теория Макклоски (McCloskey, 2006, 2010, 2016а), также и институты, и культура признаются значимыми, однако культуре присваивается ведущая роль в том числе из-за ее трансформирующего влияния на институты.

Наша главная идея состоит в том, что методологические расхождения между первой и второй группой, с одной стороны (условно, «институциональными» подходами), и третьей и четвертой группой, с другой стороны (условно, «культурными» подходами), в значительной степени объясняются скрытыми различиями в имплицитных онтологических предпосылках. Для обоснования этого тезиса в следующих разделах мы попробуем кратко изложить основные положения рассматриваемых нами теорий и выявить роль онтологических предпосылок в способах их концептуализации. В силу ограниченного объема текста мы будем вести речь только об упомянутых выше четырех теориях, так как, на наш взгляд, их можно рассматривать в качестве идеальных типов для выделенных выше четырех групп. Соответственно, это не означает, что другие существующие институциональные или культурные подходы, с нашей точки зрения, представляют меньший интерес. Тем не менее, как мы предполагаем, все они могут быть помещены в одну из четырех выделенных выше групп. 


\section{2. Институциональные подходы}

НУВ и АиР предлагают похожие аналитические схемы для понимания исторического процесса. Они базируются на дихотомии «хороших» и «плохих» политических и экономических институтов. АиР называют их, соответственно, инклюзивными и экстрактивными, а НУВ - порядками открытого и закрытого доступа. В условиях функционирования «плохих» политических институтов элитные группы ограничивают права остальных членов общества на экономическую и политическую деятельность. Тем не менее даже «плохие» политические институты лучше полной анархии, потому что они обеспечивают одно из необходимых, по мнению АиР и НУВ, условий для современного экономического роста - сильное централизованное государство.

Другим условием, обеспечивающим существование «хороших» экономических институтов, является демократия, которая понимается в обоих теориях под «хорошими» политическими институтами. Люди должны обладать возможностью формировать политические партии, выбирать своих представителей в парламент и т.д. В случае авторитаризма, «хорошие» экономические институты не в интересах властных элит, так как генерируемые благодаря им инновации ведут к эрозии извлекаемых элитами рент.

Самым важным концептуальным различием между подходами АиР и НУВ, на наш взгляд, является более элитистское восприятие политического процесса у НУВ. Если у АиР шансы трансформировать экстрактивные институты в инклюзивные связаны с формированием широкой народной коалиции, способной противостоять элитам и настоять на принятии новых правил, то у НУВ народ находится как бы на политической периферии, практически ни на что не влияет, и вся институциональная динамика исходит из внутриэлитных взаимоотношений и конфликтов. При определенном распределении потенциалов насилия между различными группами внутри элиты может оказаться, что для них выгоднее и безопаснее принять правила, допускающие открытый доступ представителей не из элиты к политическим институтам.

Важное сходство между рассматриваемыми институциональными и культурными подходами состоит в том, что все они указывают на инновации как на основу долгосрочного экономического развития и, соответственно, источник экономического успеха стран в исторической перспективе (Acemoglu, Robinson, 2012; North et al., 2009; McCloskey, 2010, 2016a; Mokyr, 2016). Однако существенными являются различия в понимании причин инноваций.

Для АиР и НУВ среди факторов инновационной деятельности основное значение имеет рента, которую извлекают инноваторы. В их логике, если институциональная система в виде «хороших» экономических институтов обеспечивает защиту прав собственности инноваторов (в том числе - интеллектуальной) и минимизирует их риски, то эко- 
номика будет процветать. У сторонников «культурных» теорий здесь взгляд несколько иной. Они не отрицают, что институты защиты прав собственности имеют важнейшее значение, но для них они являются необходимым, а не достаточным условием инноваций.

Опишем теперь кратко специфику понимания концептуальных взаимосвязей между институтами и культурой у исследуемых нами авторов. АиР разделяют культуру на две части. Первая часть - неформальные институты, которые обладают значимым влиянием на экономику (например, склонность к сотрудничеству, обобщенное доверие) и находятся в жесткой, можно сказать, функциональной, зависимости от политических институтов. Вторая часть - довольно расплывчато понимаемые остальные аспекты культуры, связанные с национальной и религиозной идентичностями.

Стоит заметить, что АиР не отождествляют свои политические и экономические институты только с формальными правилами, разделяя политическую власть на власть де-юре и де-факто (Acemoglu, Robinson, 2006). Согласно их точке зрения власть де-юре проистекает из формальных институтов - таких как конституции и электоральные системы, а власть де-факто - из возможностей использования грубой силы, коррупции, лоббизма и т.п. В результате, агенты у АиР выступают в пассивной роли, наталкиваясь на жестко закрепленные элитами де-юре и де-факто институты и постепенно корректируя свои убеждения и ожидания, чтобы соответствовать задаваемой этими институтами социально-экономической реальности.

Соответственно, культурные убеждения понимаются у АиР лишь в качестве контекста, не влияющего напрямую на социально-экономические отношения, в котором неупорядоченно объединены религия, язык, этничность, национальные традиции и региональные ценности. Причем этот контекст сам по себе статичен и меняется только в результате пассивной реакции на внешние по отношению к нему политические и экономические изменения.

Перейдем теперь к анализу взаимосвязей между элементами культурно-институциональной структуры у НУВ. Если в «Насилии и социальных порядках» (North et al., 2009) фокус внимания НУВ смещен в сторону анализа институтов и организаций, то более ранняя книга Норта «Понимание процесса экономических изменений» (North, $2005)$ почти полностью посвящена проблеме формирования культурных убеждений и их связи с институциональной динамикой.

Впрочем, и в этой книге Норт не сумел до конца сформулировать собственную теорию, особенно в области природы убеждений. В книге 2009 г. НУВ честно пишут о том, что общая теория формирования убеждений и процесса познания у них отсутствует и они рассматривают только отдельные аспекты этого процесса (North et al., 2009, p. 262). Хотя Норт и соавторы и повторяют здесь основные выводы книги Норта (Норт, 2005) в методологических разделах, культура по 
большей части у них выносится за рамки исследования, а движущей силой экономических изменений признаются изменения в институтах, через которые осуществляется контроль над насилием.

Тем не менее обратимся к основным выводам книги Норта (2005 г.). Главная идея, проходящая через всю книгу, - идея интенциональности человеческого сознания. У Норта этот концепт осмысливается через противопоставление его теории социальной эволюции дарвиновской теории эволюции (North, 2005, p. viii). Агенты в рамках дарвиновского эволюционного процесса слепы, они совершают поступки, не имея представления об их влиянии на биологическую эволюцию. Напротив, социальная эволюция, как пишет Норт, «направляется представлениями игроков. Их выбор совершается в свете этих представлений с намерением добиться результатов, снижающих неопределенность, с которой сталкиваются организации, - политические, әкономические и социальные, - преследующие свои цели» (North, 2005, p. viii).

Д. Норт попытался опереться в своей теории социальной динамики на достижения когнитивной психологии и нейробиологии. Он много рассуждает о том, каким образом протекают когнитивные процессы, и приходит к тому, что работа мозга основана прежде всего не на абстрактных логических рассуждениях, а на построении общих шаблонов для решения схожих проблем, нахождении связей и закономерностей («паттернов») в существующем опыте (North, 2005, p. 26). Человеческие убеждения и представления формируются на основе этого процесса, определяя институциональную структуру, на базе которой функционируют организации, от решений которых, в свою очередь, зависят экономические результаты общества. Благодаря тому что накопленные предыдущими поколениями паттерны сохраняются в языке, культуре и составляют базу убеждений для следующих поколений, человеческие общества способны в течение истории снижать общий уровень неопределенности, с которой они сталкиваются.

Всего Норт выделяет пять форм неопределенности: первую можно сократить через увеличение количества доступной информации при сохранении текущего объема знаний о мире; вторая требует увеличения объема самих знаний о мире; третью можно уменышить только через адаптацию существующей институциональной структуры. Четвертая форма предполагает столкновение с неизведанными ситуациями, требующими изменения существующих убеждений; наконец, пятая - остаточная неопределенность, создает почву для нерациональных убеждений, под которыми Норт имеет в виду религию, суеверия, мифы и т.п. (North, 2005, p. 17).

С точки зрения Норта, всегда будут происходить уникальные ситуации и возникать проблемы, разрешить которые будет нельзя, опираясь только на предыдущий опыт (North, 2005, p. 16). Человечество с течением времени продолжает успешно сокращать неопределен- 
ность, связанную с физическим миром. Однако наряду с ней Норт выделяет еще одну неопределенность, связанную с человеческим поведением, которая со временем только увеличивается, из-за чего отражение реальности в убеждениях никогда не будет абсолютно полным. Анализируя рост неопределенности социальных систем, Норт использует концепцию Хайека о распределенном знании: вместе с усложнением экономических систем и возрастанием уровня специализации доступное отдельному человеку знание становится более локальным, поэтому для интеграции знания на социальном уровне становятся необходимыми более сложные институты.

В целом позиция Норта касательно природы убеждений представляется неоднозначной. В книге 2009 г. НУВ пишут о том, что убеждения людей по большей части определяются внешними институтами или организациями (North et al., 2009, p. 262), хотя в книге Норта (2005 г.), как мы убедились, акценты расставлены несколько иначе. Вообще говоря, расплывчатость и взаимовлияние этих социальных феноменов позволяет Норту и его соавторам, несмотря на большое внимание к убеждениям в теоретических и методологических разделах работ, фактически оставить их в стороне при разработке конкретных кейсов и оперировать в них главным образом системами стимулов, задаваемых институтами. В результате их имплицитная методологическая программа и полученные выводы становятся очень близкими теории АиР, о чем в том числе пишет Р.И. Капелюшников (Капелюшников, 2019): инклюзивные институты в основных чертах совпадают с порядками «открытого доступа», а экстрактивные институты - с порядками «ограниченного доступа», хотя, безусловно, разница в отдельных аспектах и расставленных авторами акцентах присутствует.

\section{3. Культурные подходы}

Выше мы отмечали, что для Мокира и Макклоски рост инноваций в меньшей степени связан с ростом ренты инноваторов. $\mathrm{C}$ их точки зрения, большее значение, по крайней мере в исторической перспективе, имели определенные эпистемические и этические установки соответственно.

Так, по Мокиру, причиной всплеска инноваций было фундаментальное изменение способа восприятия мира у европейской научной элиты в XVI-XVII вв., во второй половине XVIII в. распространившееся среди практиков-инноваторов (Mokyr, 2016). Появившийся тогда новый тип мышления предполагал веру в существование прогресса, убежденность в превосходстве современных образцов над древними, важность прикладного аспекта науки, понимание мира как управляемой познаваемыми законами системы, а математику - как главный язык описания этих законов.

Ключевыми в методологии Мокира являются концепты рынка идей, культурного предпринимательства и культурной эволюции 
на основе выбора (choice-based cultural evolution). По Мокиру, культура развивается в рамках эволюционного процесса, который по своей природе является скорее ламаркианским, а не дарвиновским. Дарвинистские теории Одеда Галора (Galor, 2011) и Грегори Кларка (Clark, 2007) имплицитно предполагают, что дети являются абсолютными культурными копиями своих родителей, полностью перенимая у них убеждения и ценности в ходе первичной социализации, а экономические изменения происходят вследствие вытеснения из популяции представителей с «худшим» набором культурных и генетических характеристик «более успешными» представителями популяции, обладающими характеристиками, способствующими әкономическому развитию.

Мокир не согласен с таким подходом - если перенимаемые в раннем возрасте свойства еще можно представить в виде копируемых в дарвиновском духе, то все дальнейшие изменения культурного фенотипа связаны со свободным выбором перенимать (или не перенимать) появляющиеся в доступном культурном меню новые убеждения.

Для описания набора доступных человеку для выбора убеждений Мокир использует понятие рынок идей. Он указывает, что это всего лишь метафора: «рынок идей» нельзя назвать настоящим рынком, так как на нем сложно найти адекватные эквиваленты для таких ключевых составляющих любого рынка, как бюджетное ограничение и цены (Mokyr, 2016). Тем не менее Мокир считает эту метафору полезной, так как мы можем исследовать конкуренцию на рынке идей, наличие на нем барьеров для входа, трансакционных издержек, запретов, регуляций и эффективности.

Кроме того, мы можем указывать на действующих на нем предпринимателей - культурных предпринимателей. Эти особые агенты, в теории Мокира, обладают способностью генерировать новые идеи, расширяя набор доступных опций в культурном меню у других людей. Цель культурных предпринимателей - максимально широкое распространение своих идей. Среди упоминаемых Мокиром примеров культурных предпринимателей есть такие исторические личности, как Пророк Мухаммед, Мартин Лютер, Адам Смит, Карл Маркс, Чарльз Дарвин и находящиеся в центре его теории фигуры Фрэнсиса Бэкона и Исаака Ньютона.

Мокир перечисляет факторы, называемые им смещениями (biases), которые могут способствовать решению детей отказаться от убеждений своих родителей или определенным образом их трансформировать (Mokyr, 2016, p. 48-56). К таким факторам относятся: появление новых, более убедительных, фактов и теорий (content-based bias); авторитетное мнение уважаемых в обществе людей (direct bias); необходимость соединять разные убеждения в единую непротиворечивую картину мира (consistency and confirmation bias); имитация поведения людей, выступающих в качестве ролевых моделей (model-based bias). 
Сюда же Мокир относит методики убеждения и способы представления информации (rhetorical bias, framing); мнение большинства людей вокруг (frequency dependence bias); рационализацию, интернализацию существующих формальных институтов (rationalization bias); силовое принуждение и насильственную пропаганду (coercion bias), а также важные события (salient event bias).

Как считает Мокир, в Европе в XVII-XVIII вв. сформировался институт, серьезно увеличивший стимулы культурных предпринимателей выдвигать идеи, и в частности поспособствовавший появлению и распространению среди интеллектуальной элиты определенных новых идей, которые и привели к наступлению эпохи современного экономического роста. В истории научной коммуникации за этим институтом закрепилось название «Республика писем» (Republic of Letters). Республика была по большей части виртуальной социальной сетью, объединявшей ученых из разных стран Европы, которые вели между собой постоянную научную дискуссию с помощью рукописных писем. Ее важность, по мнению Мокира, заключалась в том, что она обеспечивала конкуренцию между идеями, расширяла возможности для сотрудничества между учеными и кругом потенциальных носителей новых идей, снижала барьеры для входа на рынок идей, способствовала выработке стандартов научной риторики.

Так же, как и Мокир, Макклоски отмечает изменения убеждений, но у нее речь идет не о способах познания мира, а о внутренней мотивации. С ее точки зрения, причиной наступления современного экономического роста в Великобритании и Нидерландах стало изобретение там новой, «буржуазной», этики (McCloskey, 2006, 2010, 2016a). Ее важными элементами, отличающимися от господствовавшей прежде аристократической этики, согласно Макклоски, являются признание всех людей обладающими равным достоинством и уважение деятельности предпринимателей-инноваторов со стороны общества. Появление буржуазной интерпретации добродетелей было уникальным событием для XVIII в. Оно, с точки зрения Макклоски, стало возможным во многом благодаря продвижению в сторону равенства в разных сферах жизни в Европе XVI-XVII вв.

Макклоски стремится уйти от традиционного для экономической науки методологического индивидуализма при обращении к культуре - по ее мнению, культура не сводится только к изолированному индивидуальному выбору, равно как она не свойственна понятому в холистическом духе обществу. Культура обладает интерсубъективной природой - она возникает как бы между людьми.

Ее позиция близка к позиции Мокира с той точки зрения, что они оба фокусируют внимание на идеях. Однако способ понимания культуры как набора индивидуальных убеждений с точки зрения теории Макклоски выглядит несколько упрощенным. Ее привлекают скорее не привязанные к отдельным людям установки, а распыленные 
в общественном мнении, в общественном дискурсе образы, истории, риторические обороты, метафоры (McCloskey, 2016a, 2016b).

Попытки исследования культуры и институтов, опирающиеся на нейробиологию, подобные предпринятым, по ее мнению, Дугласом Нортом, представляются Макклоски не слишком перспективными, в том числе из-за ее частичного отказа от методологического индивидуализма. Ссылаясь на невролога Рэймонда Таллиса, она утверждает, что социальные явления являются эмерджентным феноменом, возникающим в процессе взаимодействия множества людей, и их нельзя вывести из анализа работы мышления отдельного индивида (McCloskey, 2016b, p. 17-18).

В то же время Норт высказывал похожие мысли, цитируя следующую фразу антрополога Эдвина Хатчинса: «Культура, контекст и история... являются фундаментальными аспектами человеческого познания и не могут с легкостью быть интегрированы в направление исследований, для которого приоритетом являются абстрактные характеристики изолированного индивидуального мышления» (North, 2005, p. 33-34). Но понимание культуры у Норта ближе к холистическому: культура у него выступает своего рода надындивидуальным регулятором, обеспечивающим рациональный выбор и постепенную адаптацию к изменяющимся условиям на уровне общества (например, (North, 2005, p. 24, 36)). Макклоски же не рассматривает культуру только как инструмент адаптации - культура для нее экзогенна по отношению к экономике, она может быть подвержена влиянию экономических факторов, но принципиально не сводима к ним.

Что касается «институтов», то это понятие Макклоски в своих текстах использует в двух контекстах. В полемике с неоинституционалистами она под институтами имеет в виду формальные институты, критикуя подходы АиР и НУВ, согласно которым именно изменение формальных институтов было главной причиной современного экономического роста. В собственной же теории она склоняется к пониманию институтов как статус-функций Джона Серля: институты не просто ограничивают пространство доступных опций для поведения, а создают возможности для принципиально новых типов поведения (McCloskey, 2016b).

Исследовательскую ценность концепта «неформальные институты» Макклоски оценивает низко, так как, по ее мнению, теория из-за необходимости неформального способа обеспечения исполнения нормы рискует скатиться к тавтологическому утверждению типа «социальные изменения зависят от общества» (McCloskey, 2016a, p. 114). Более того, исполнение формальных институтов всегда требует интерпретации правильной процедуры их применения, что делает их менее устойчивыми ограничениями (McCloskey, 2016b).

Несмотря на то что Макклоски в своей риторике активно спорит с неоинституционализмом, она во многом продолжает идеи, выска- 
занные в рамках именно этой традиции. Ее ключевая мысль состоит в том, что начало современного экономического роста было связано с формированием либерализма, утвердившего представление, согласно которому все люди являются равными друг другу в этическом смысле, а мир социальных взаимодействий представляет собой игру с положительной суммой (McCloskey, 2016a). Этот комплекс идей противоречил господствовавшему до этого восприятию социальной реальности в виде иерархии и игры с нулевой суммой. Схожая мысль была высказана Нортом, который писал о том, что переход от представления взаимоотношений человека с миром как игры с нулевой суммой к представлению об игре с положительной суммой был «критической поворотной точкой в процессе экономических изменений» (North, 2005, p. 63-64).

Макклоски вносит динамичность в свое понимание культуры, делая акцент на языке и повседневности. Публичные разговоры, общественное мнение и стереотипы, актуальные литература, театр, архитектура, изобразительное искусство, кино - вот что отражает реально происходящую в данный момент культуру и влияет на поступки людей (McCloskey, 2006, 2016a). Макклоски для описания всего этого текущего культурного процесса использует термин «поверхностная риторика» ("superficial rhetoric"), противопоставляя ее наследуемым историческим культурным характеристикам (McCloskey, 2016a, p. 499).

Безусловно, в формировании буржуазного этического нарратива в Великобритании и Нидерландах, связываемого Макклоски с наступлением современного экономического роста, большую роль сыграла уже существовавшая на тот момент богатая европейская культура. Однако, с точки зрения Макклоски, в этом не было ничего заранее предопределенного, оптика механических причинно-следственных связей здесь не работает. Наследуемая европейцами из прошлого культура выступала только в качестве фундамента, материала для создания и воспроизводства истории о добродетельном буржуа.

Таким образом, по Макклоски, даже если наследуемые традиции и не меняются, то влияющая на жизнь человека часть культуры изменчива и динамична, творясь в реальном мире разговаривающими и пишущими людьми. В области «поверхностной риторики» возникают образцы, метафоры и истории добродетельной жизни, которые люди выбирают в качестве этических ориентиров.

\section{4. Предпосылки относительно мотивации агентов как скрытый источник разногласий}

При сравнении институциональных теорий с культурными можно заметить, что первые имеют скорее дедуктивный характер построения, а вторые - скорее индуктивный. Институциональные теории основаны на наборе политико-экономических моделей, глубоко проработанных на формальном уровне (в случае АиР), которые являются элементами большого единого объясняющего механизма. 
Затем этот механизм преобразуется в своего рода универсальный аналитический нарратив, используемый для интерпретации исторических событий.

Этот механизм, как и в стандартной неоклассической экономической теории, выводится исключительно из базовых предпосылок о поведении. АиР и НУВ избегают непосредственного описания внутренней мотивации своих агентов, по всей видимости, полагая, что модель экономической рациональности в условиях их теорий по-прежнему применима. На наш взгляд, перенос этой модели из стандартного поля экономической теории в область исследования общих исторических закономерностей требует существенной трансформации исходной модели.

Попытку эксплицитного описания этой фактически новой модели человека можно обнаружить у А.С. Скоробогатова, когда он пишет о расширительном понимании "экономического человека" в исторической науке, в рамках которого человек остается эгоистом, однако теперь она или он могут применять насилие для достижения своих целей (Скоробогатов, 2017).

Научную обоснованность использования традиционной модели «эгоистичного» homo economicus вполне можно подвергать сомнению, опираясь на свидетельства из литературы по экономической психологии (Fehr, Fischbacher, 2002; Charness, Rabin, 2002). Однако, на наш взгляд, определение Скоробогатова отчасти верно для теорий АиР и НУВ, которые по существу сохраняют стремление к личной выгоде в качестве базового описания мотивации в своих аналитических нарративах. Вместе с тем, с нашей точки зрения, описания Скоробогатова недостаточно, поскольку предпосылки о наличии правовых институтов рыночной экономики, нуждающиеся, как он справедливо пишет, в пересмотре при изучении истории с помощью модели «человека экономического», определяют не только ненасильственный характер поступков агентов, но и имплицитно задают их интересы. Мы можем говорить о стремлении к максимальной прибыли или максимальной полезности при потреблении в контексте моделей рыночных отношений, из чего совсем не будет следовать, что универсальная мотивация является эгоистической или гедонистической. Поэтому, опираясь на логику экономической рациональности в контексте общей исторической динамики, объяснение которой уже, в свою очередь, требует универсально задаваемой мотивации, авторы вольно или невольно совершают подмену, предлагая нам не пустой и инструментальный эгоизм экономической теории, а более содержательную с антропологической точки зрения его трактовку.

Нам представляется, что модель человека в подходах АиР и НУВ наиболее близка представлению Томаса Гоббса, в видении которого люди предстают склонными к насилию оппортунистами, беспокоящимися исключительно о собственных материальных интересах и без- 
опасности (Hobbes, 1946). На основе модели человека Гоббса строится конфликтная модель общественных отношений, объясняющая исторические изменения через основанную на насилии борьбу индивидуальных интересов за ресурсы и власть.

Одним из важных для нас следствий универсальности мотивации агентов является детерминированный характер их действий. Благодаря этой детерминированности и предсказуемости поведения агентов авторы могут описывать общую логику исторического процесса, используя конкретные исторические события лишь в качестве иллюстраций для подтверждения этой общей логики. В конечном счете, при последовательном проведении такого детерминизма все экзогенные причины исторической динамики должны сводиться к ограничениям, обусловленным географией и природными процессами. К аналогичному выводу приходят Алесина и Джулиано во введении к их методологической статье: «Культура и институты являются эндогенными переменными, определяемыми, предположительно, географией, технологией, эпидемиями, войнами и другими историческими шоками» (Alesina, Giuliano, 2015, p. 2).

Применяя такую оптику для интерпретации взглядов Норта, мы должны дать дополнительные пояснения. Дело в том, что Норт пытается уйти от детерминизма, однако постулируемая Нортом неопределенность, с нашей точки зрения, фундаментальным образом отличается от неопределенности, которую мы можем обнаружить в культурных теориях Мокира и Макклоски.

И.В. Розмаинский выделил два типа возможной неопределенности будущего в экономической теории: эпистемологическую и онтологическую (Розмаинский, 2016). Если первая связана с экстремально высокими издержками получения достоверной информации о будущем, которое при этом теоретически может быть познаваемым, то вторая связана с тем, что часть нужной информации еще просто не создана, что делает будущее принципиально непознаваемым. Онтологическую неопределенность, согласно Розмаинскому, мы обнаруживаем в том числе и у Норта.

Как пишет Розмаинский, в онтологически неопределенной реальности свобода воли играет очень важную роль (Розмаинский, 2016, с. 38). В то же время, на наш взгляд, эта роль может быть различной, в результате чего мы можем иметь дело с разными видами онтологической неопределенности.

В теории Норта люди способны замышлять и реализовывать проекты изменения мира и общества, просчитывая и полностью осознавая их последствия, но не способны в исторической перспективе считать реализацию этих проектов ценностью самой по себе. Норт, связывая убеждения с необходимостью сокращения неопределенности и называя, например, религию формой иррациональности, появляющейся из-за недостатка логически последовательных и доступных для 
эмпирической верификации убеждений (North, 2005, p. 16), фактически предлагает нам картину мира, в которой идеи и убеждения отражают только доступную человеку информацию о мире.

Как и эпистемические убеждения, этические установки Норт трактует как своего рода накопленную на надындивидуальном уровне информацию об оптимальном способе адаптации сообщества к окружающей среде. В результате планы и замыслы отдельных людей оказываются частным непреднамеренным выражением этого стремления к адаптации.

На выходе мы имеем ситуацию своеобразной биологизации культуры, в которой исходная модель человека Гоббса модифицируется с помощью метафоры биологической адаптации. Источником онтологической неопределенности у Норта остается только неполная предсказуемость поведения человеческого когнитивного аппарата при решении возникающих перед ним проблем, которая создает небольшое пространство для свободного выбора.

Фундаментальное отличие теорий Мокира и Макклоски состоит в том, что действия агентов в них нельзя выразить через набор внешних ограничений, когнитивные способности, доступную агентам информацию и мотивацию по Гоббсу. Существуют некоторые неуниверсальные автономные факторы, выступающие в качестве элементов внутренней мотивации агентов. Это вынуждает строить аналитические нарративы на основе индуктивной культурно-исторической аргументации, являющиеся более чувствительными к временному и страновому контексту.

Авторы не отрицают важной роли внешних ограничений и адаптации к окружающей среде, но не сводят к ним все поведение агентов. Согласно их теориям агенты способны свободно генерировать и распространять идеи, следовать этим идеям, считая их именно ценностью, независимой от целей выживания, потребления и господства. Мокир учитывает эту дополнительную неопределенность с помощью концептов культурного предпринимательства и культурных смещений (см., например, обсуждение в (Shiller, 2017)). У Макклоски неопределенность проистекает из метафорической природы языка. И эпистемические идеи, расширяющие знание, и этические идеи, изменяющие мотивацию, нуждаются в интерпретации, благодаря чему возникает пространство свободной и контекстуальной мотивации.

Нам представляется, что именно здесь появляется возможность описать искомое различие в онтологических предпосылках между культурными и институциональными подходами. На наш взгляд, оно заключается в том, допускает ли теория устойчивые экзогенные шоки во внутренней мотивации агентов. Институциональные подходы возможность таких шоков отвергают, всегда отталкиваясь от универсальной мотивации по Гоббсу, которая может как-то изменяться только вследствие эндогенных процессов в рамках модели. В то же время культур- 
ные подходы могут рассматривать такие экзогенные шоки как самостоятельные элементы каузальных цепочек.

Авторам всегда доступна редукционистская стратегия, в которой внутренняя мотивация агентов сводится к каким-то внешним (по отношению к агентам) факторам и универсальным поведенческим или биологическим законам. Институциональные подходы характеризует как раз подобный редукционизм, в отличие от культурных подходов, которые рассматривают внутреннюю мотивацию в качестве самостоятельного объекта исследования.

Из-за невозможности в рамках институциональных подходов экзогенных шоков во внутренней мотивации идеи в них приравниваются к информации. Между тем мы часто можем констатировать неразрывные связи между когнитивной и нормативной составляющими многих идей, совмещающих в себе как информацию о мире, так и предписание о правильном поведении - от этой интуиции отталкиваются культурные подходы.

\section{5. Заключение}

Выявленное расхождение ведет к тому, что авторы институциональных теорий из-за своей редукционистской оптики недооценивают возможную роль новых идей и нарративов в политических и экономических изменениях. Практическое игнорирование данного класса объяснений этими подходами часто может служить основанием для обвинения их в слепоте и нечувствительности по отношению к историко-культурному контексту, в неоправданной подгонке реальных исторических событий под свои абстрактные каузальные модели.

В то же время авторы культурных теорий из-за своей иногда излишней чувствительности к контексту могут впадать в другую крайность: тавтологию, игнорирование растянутых во времени сложных причинно-следственных взаимосвязей, невозможность генерализации полученных результатов. В этом, в частности, можно упрекнуть Макклоски. Во-первых, с существенным риском скатывания в тавтологию связана ее попытка объявить конечной причиной Промышленной революции культуру предшествовавших ей нескольких десятилетий. И, во-вторых, подобное объяснение испытывает серьезные проблемы при его перенесении в другой историко-культурный контекст, например при объяснении әкономического взлета Китая на рубеже XX-XXI вв.

В этом смысле нельзя отдать однозначное предпочтение ни институциональным, ни культурным теориям. Тем не менее, на наш взгляд, допускающие экзогенные шоки во внутренней мотивации культурные подходы с методологической точки зрения более перспективны в силу своей большей плюралистичности: уделяя внимание идеям и нарративам, они не игнорируют роль факторов, на которые опираются институциональные подходы, что существенно расширяет 
спектр доступных объясняющих механизмов. Например, с нашей точки зрения, Мокиру в его теории удается умело балансировать между контекстуальными культурными факторами (роль культурных предпринимателей) и институциональными ограничителями (роль «Республики писем» и обусловивших ее появление структурных факторов - подробнее см. в (Mokyr, 2016)).

На наш взгляд, важность онтологических предпосылок относительно внутренней мотивации агентов не ограничивается только их ролью в формировании разногласий между институциональными и культурными подходами. Наряду с этим, как нам представляется, в зависимости от выбранных предпосылок исследователи привлекают методы из различных дисциплин в свои работы междисциплинарного толка. Так, предпосылка об экзогенных шоках в мотивации ведет к необходимости содержательного анализа возникающих в результате этих шоков различающихся человеческих идентичностей с помощью культурологии, социологии, социальной антропологии, истории. Напротив, предпосылка об универсально задаваемой мотивации подталкивает исследователей к поиску общих оснований поведения в таких науках, как нейробиология и эволюционная биология.

Если попытаться сделать более прикладные выводы из этого исследования, то можно констатировать, что наше отношение к роли публичной дискуссии в экономическом развитии будет зависеть от того, считаем ли мы внутреннюю мотивацию абсолютно устойчивой и неизменимой. Так, в том случае, когда воздействие на внутреннюю мотивацию с помощью убеждения представляется нам невозможным, публичное обсуждение общественных проблем будет пониматься исключительно как процесс согласования интересов, содержание которых само по себе не имеет значения, его имеет только институциональная форма, т.е. то, в какой мере различные группы могут отстаивать свои интересы в рамках этой дискуссии. Если же внутренняя мотивация представляется нам более изменчивой, то альтернативным путем достижения общего блага, наряду с согласованием интересов, будет убеждение, успешность которого напрямую зависит от содержания публичного сообщения. Таким образом, в последнем случае само состояние публичной дискуссии с характерными для него идеями и нарративами, а не только регламентирующие данную дискуссию институциональные правила, приобретает существенное значение.

\section{ЛИТЕРАТУРА / REFERENCES}

Ананьин О.И. (2013). Онтологические предпосылки экономических теорий. М.: Институт экономики РАН. [Ananyin O. (2013). Ontological premises of economic theories. Moscow: Institute of Economics, RAS (in Russian).]

Капелюшников Р.И. (2019). Contra панинституционализм. Часть I / / Вопросы экономики. № 7. С. 119-146. [Kapelyushnikov R. (2019). Contra paninstitutionalism. Part I. Voprosy Ekonomiki, 7, 119-146 (in Russian).] 
Розмаинский И.В. (2016). Посткейнсианцы и Дуглас Норт о неопределенности и институтах: пропущенная связь? / / Журнал институииональных исследований. № 8 (3). C. 35-46. [Rozmainskij I. (2016). Post Keynesians and Douglass North on Uncertainty and Institutions: A Missing Link? Journal of Institutional Studies, 8 (3), 35-46 (in Russian).]

Скоробогатов A.C. (2017). Силовой потенциал и формы рационального поведения (опыт экономики истории) // Историко-экономические исследования. № 18 (3). C. 511-544. [Skorobogatov A. (2017). Power potential and forms of rational behavior (experience of the economics of history). Journal of Economic History and History of Economics, 18 (3), 511-544 (in Russian).]

Тамбовцев В.Л. (2019). Идеи, нарративы и изменения в экономике // Terra Economicus. № 17 (1). C. 24-40. [Tambovcev V. (2019). Ideas, Narratives and Changes in the Economy. Terra Economicus, 17 (1), 24-40 (in Russian).]

Acemoglu D., Robinson J.A. (2006). De facto political power and institutional persistence. American Economic Review, 96 (2), 325-330.

Acemoglu D., Robinson J.A. (2012). Why nations fail: The origins of power, prosperity, and poverty. N.Y.: Crown Business.

Allen R.C. (2015). The high wage economy and the industrial revolution: A restatement. The Economic History Review, 68 (1), 1-22.

Alesina A., Giuliano P. (2015). Culture and institutions. Journal of Economic Literature, 53 (4), 898-944.

Boudreaux D.J. (2014). Deirdre McCloskey and economists' ideas about ideas. Liberty Matters. Available at: https:/ / oll.libertyfund.org/pages/lm-mccloskey

Charness G., Rabin M. (2002). Understanding social preferences with simple tests. The Quarterly Journal of Economics, 117 (3), 817-869.

Clark G. (2007). A farewell to alms: A brief economic history of the world. Princeton: Princeton University Press.

Diamond J.M. (1998). Guns, germs and steel: A short history of everybody for the last 13,000 years. London: Vintage.

Fehr E., Fischbacher U. (2002). Why social preferences matter - the impact of nonselfish motives on competition, cooperation and incentives. The Economic Journal, 112 (478), C1-C33.

Galor O. (2011). Unified growth theory. Princeton: Princeton University Press.

Greif A., Mokyr J. (2016). Institutions and economic history: A critique of professor McCloskey. Journal of Institutional Economics, 12 (1), 29-41.

Hobbes T. (1946). Leviathan; or, the matter, form and power of a commonwealth, ecclesiasticall and civil. New Haven: Yale University Press.

McCloskey D.N. (2006). The bourgeois virtues: Ethics for an age of commerce. Chicago: University of Chicago Press.

McCloskey D.N. (2010). Bourgeois dignity: Why economics can't explain the modern world. Chicago: University of Chicago Press.

McCloskey D.N. (2016a). Bourgeois equality: How ideas, not capital or institutions, enriched the world. Chicago: University of Chicago Press.

McCloskey D.N. (2016b). Max U versus Humanomics: A critique of neoinstitutionalism. Journal of Institutional Economics, 12 (1), 1-27. 
McCloskey D.N. (2017). Neo-institutionalism is not yet a scientific success: A reply to Barry Weingast. Scandinavian Economic History Review, 65 (2), 116-123.

Mokyr J. (2016). A culture of growth: The origins of the modern economy. Princeton: Princeton University Press.

Mokyr J. (2018). Bottom-up or top-down? The origins of the Industrial Revolution. Journal of Institutional Economics, 14 (6), 1003-1024.

North D.C. (2005). Understanding the Process of Economic Change. Princeton: Princeton University Press.

North D.C., Wallis J.J., Weingast B.R. (2009). Violence and social orders: A conceptual framework for interpreting recorded human history. N.Y.: Cambridge University Press.

Shiller R.J. (2017). Narrative Economics. American Economic Review, 107 (4), 967-1004.

Tabellini G. (2016). Ideas or institutions? - A comment. Journal of Institutional Economics, 12 (1), 43-48.

Weingast B.R. (2016). Exposing the neoclassical fallacy: McCloskey on ideas and the great enrichment. Scandinavian Economic History Review, 64 (3), 189-201.

Поступила в редакиию 6.02 .2020

Received 6.02.2020

M.B. Bakeev

Centre for the History and Methodology of Economic Science Studies, NRU HSE, Moscow, Russia

\section{Institutional and cultural research directions in development economics: Assumptions on agent motivation as a source of disagreement}

Abstract. In this paper we address the methodological discrepancies that exist between institutional and cultural approaches in modern literature devoted to the study of reasons for economic development in the long historical perspective. We analyze in detail and compare the ontological assumptions of the theories of key representatives of the institutional (D. Acemoglu, J. Robinson and D. North) and cultural research directions (J. Mokyr, D. McCloskey). We show that traditional ways of conceptualizing are insufficient for understanding the actual source of methodological disagreements existing between these approaches. We argue that the reason for such disagreements is the difference in implicit ontological assumptions regarding the motivation of agents between the theories under consideration. The authors of institutional theories, who do not consider it necessary to assign an independent role to cultural factors along with institutional ones, at the level of ontological assumptions reject the possibility of exogenous changes in the internal motivation of agents. At the same time, the authors of cultural theories, who distinguish institutional and cultural factors as independent from each other, in their theories acknowledge the presence of exogenous shocks of internal motivation and their potentially important role in economic changes. This discrepancy determines, on the one hand, the deductive nature of analytical narratives within the institutional research direction, and on the other hand, the inductive nature of the historical argumentation of representatives of the cultural research direction.

Keywords: institutions, culture, economic development, ideas, ontological assumptions, scientific disputes, motivation.

JEL Classification: B2, B4, B5, N10, O11, O31, Z13.

DOI: $10.31737 / 2221-2264-2020-46-2-7$ 